\title{
MATING DISRUPTION OF PINK BOLLWORM, PECTINOPHORA GOSSYPIELLA (SAUNDERS) USING PB ROPE DISPENSERS IN COTTON GROWING AREAS OF PUNJAB, PAKISTAN
}

\author{
Zulfiqar Ali Ghauri' ${ }^{1}$, Habib Anwar ${ }^{2}$, Faqir Ahmad ${ }^{3}$ \\ ${ }^{1}$ Pest Warning \& Quality Control of Pesticides, Sialkot, Punjab, Pakistan. \\ ${ }^{2}$ Pest Warning \& Quality Control of Pesticides, Chiniot, Punjab, Pakistan. \\ ${ }^{3}$ Pest Warning \& Quality Control of Pesticides, Lahore, Punjab, Pakistan.
}

\section{A R T I C L E I N F O}

\section{Article history}

Received: June 02, 2019

Revised: September 14, 2019

Accepted: December 15, 2019

\section{Keywords}

Pectinophora gossypiella

PB rope

Mating disruption

Leftovers

\section{A B S T R A C T}

\begin{abstract}
Pink bollworm, Pectinophora gossypiella (Saunders), (Lepidoptera: Gelechidae) is considered as a notorious and destructive pest in the world and can reduce cotton yield up to $30 \%$ if not managed properly. Insect pest management through mating disruption technique offers practically an ideal approach to combat the pests. In the present study, the efficacy of mating disruption dispensers (PB rope L) for the management of pink bollworm was evaluated and the percent infestation in bolls and leftover bolls was determined in the cotton growing areas of Punjab, Pakistan during 2017. The PB ropes @100 per acre were used for each treated field of approximately 50 acres with a block of 10 acres as a control plot in the same union council of the treated plot. Calculation was made by comparing infestation and cotton yield in treated field with that of control field. The PB rope significantly reduced both the number of males in the sex pheromone traps and cotton bolls damage. Results revealed that PB rope during the first pin square period (45 days after sowing) effectively minimized the damage even in leftover bolls. The yield of treated field was enhanced compared with control field by $31 \%$ in 2017. Infestation in leftover bolls was estimated by comparing cotton bolls collected from control field with bolls from the treated field. The results reflected $1.56 \%$ damage in control field and $0.30 \%$ damage in treated field with a difference of 1.26 (80\% reduction in damage in treated plots). Result indicated that PB rope disrupted the pest mating effectively during July to October.
\end{abstract}

Corresponding Author: Zulfiqar Ali Ghauri

Email: zaghoriada@gmail.com

(C) 2019 EScience Press. All rights reserved.

\section{INTRODUCTION}

Cotton (Gossypium hirsutum L.) is an important fiber and cash crop of Pakistan. It is regarded as a vital source of foreign exchange which comes through exporting surplus raw cotton. Pakistan occupies fourth position in terms of production among major cotton producing countries of the world (Abro et al., 2004). Cotton accounts for $2.4 \%$ of GDP. About $35 \%$ of edible oil production comes from cotton seed. Moreover, livelihood of millions of people in the country depends 
directly or indirectly upon cotton. The average per hectare yield of cotton in Pakistan is low as compared to other nations of the world (Bakhsh et al., 2005).

Biotic and abiotic stresses and competition from other crops have reduced the cotton production. The area and production of cotton in Punjab during 2011-12 was 6.261 million acres and 11.129 million bales respectively which decreased to 5.582 million acres and 6.593 million bales during 2015-16 with further decline to 44.388 million acres during 2016-17. This particular situation demands effective solution of the problems on sustainable basis which can lead to the revival and increased productivity with available resources.

Among various factors responsible for low yield of cotton, insect pests are the most important factors causing up to 30-40\% yield loss (Agarwal and Katiyar, 1979; Kannan et al., 2004). These include sucking as well as chewing insect pest complex. Among chewing insect pests, pink bollworm (PBW), Pectinophora gossypiella (Saunders) (Lepidoptera: Gelechidae) is considered as a notorious and destructive pest in the world (Darling, 1951; Ingram, 1994). This single pest can reduce cotton yield up to $30 \%$ if not managed properly. Larvae of the pink bollworm feeds upon cotton squares, blooms and seeds within the growing boll and causes heavy loss to cotton in terms of destruction of lint and seeds, which degrade the quality of cotton. A detailed review has been made by Parmar and Patel (2016).

Alternate control strategy such as mating disruption with synthetic pheromone (PB ropes L) is the use of behaviour modifying chemical i.e. Gossyplure. Hummel et al. (1973) investigated gossyplure, a 1:1 mixture of the Z, Z- and Z, E-isomers of 7, 11-hexadecadienyl acetate is natural sex pheromone of pink bollworm. The female pink bollworm releases gossyplure to attract males. Pheromone traps are used to monitor the pests, as a tool to capture insects, as confusants to disrupt insect mating and as lures to attract insects to insecticidal baits (Byers and Steven, 2014). Its scent confuses the male adults preventing them from finding and mating with the female adults resulting in less number of fertile eggs of PBW and crop damage.

Gossyplure has been demonstrated for monitoring PBW and extensively employed for mating disruption of PBW moths (Buchelos et al., 1999; Campion and Nesbitt, 1982; Urquijo and Manzano, 2002). Mating disruption is achieved when gossyplure is dispersed at high doses in cotton canopy and can reduce damage levels of the pest in cotton (Kehat et al., 1999). PB-rope dispensers provide high dose-rate release of pheromone over a period that significantly decrease moth catches in traps (El-Deeb et al., 1993; Flint et al., 1985; Staten et al., 1987). Insect pest management through mating disruption technique offers practically an ideal approach to combat the pests (Henneberry and Naranjo, 1998; Patil et al., 2004). Toxic chemicals are being used indiscriminately and haphazardly to control the pests which have not only threatened the human health of the producers, workers and consumers but also created quick resistance in the insect pests resulting in adverse effect on the efficacy of the product due to which the control of pests has become very difficult. Haphazard spray application also harm the natural enemies of the pest to cause imbalance in ecosystem. Similarly, the blind use of insecticides also increases the price of the product. Under such situation, alternate control strategy (PB ropes) is the safest technique to manage insect pests. Keeping in view, male disruption technique with the help of Gossyplure and PB ropes has been used as an alternate method to control PBW without damaging the natural enemies as well as environment.

The present study was carried out to evaluate the efficacy of PB ropes as mating disruptor in treated and control plots at farmer fields with reference to percent infestation in bolls, infested leftover bolls and yield assessment.

\section{MATERIALS AND METHODS}

Cotton growing areas of Punjab, Pakistan was taken as type universe to conduct the study. All districts of five divisions (Multan, Bahawalpur, Sahiwal, Dera Ghazi Khan and Faisalabad) were selected for the installation of mating disruption dispensers. Fifty acre plot was selected in each of 50 tehsils for installing PB ropes while control plots each of 10 acres were set located at 600-800 $\mathrm{m}$ away from the respective treated plots in the same union council. Treated and control fields were almost surrounded by cotton fields. PB ropes were installed @ 100 per acre in a block of 50 acres in each tehsil of cotton growing districts.

The PB rope dispensers were tied manually by twisting the dispenser around the stem of the cotton plants at first pin square (45 days after sowing). Five sex pheromone traps were also installed in treated plots @ 1 trap per 10 acres. One sex pheromone trap was also installed at each of the control plot (a block of 10 acres) for the evaluation of the efficacy of PB 
ropes at treated plots.

The infestation by PBW was recorded by prescribed pest scouting methods (Hussain R., 2017) through collection of randomly selected bolls in both treated and control plots. The samples were critically and carefully examined for the presence of or damage caused by PBW larvae. The data were recorded on weekly basis in a sequence from July to October 2017. After the last harvest of October 2017, leftover bolls were also collected by random sampling for dissection from treated and untreated plots to observe the presence of PBW larvae. The yield was also calculated in both treated and non-treated plots in maunds per acre.

Statistical analysis: Data were analyzed statistically by using $\mathrm{R}$ version 3.4 .3 (Kite-Eating Tree). ANOVA comparison between districts and weeks were made by using 2 factors CRD.

\section{RESULTS}

Boll infestation by pink bollworm: District and week wise data of infestation by pink bollworm was recorded and analyzed statistically by applying ANOVA (Table 1). Figure 1 indicates that overall infestation by pink bollworm in all the control plots was significantly more than that of the treated plots. Average infestation in Rajanpur on control plot was observed $2.71 \%$ as compared to $0.00 \%$ in treated plot followed by $2.59 \%$ in Bahawalnagar on control plot versus $0.19 \%$ in treated field. Lowest infestation of $0.24 \%$ in control plot was observed in district Layyah as compared with $0.03 \%$ in treated plot.

Table 1. Analysis of variance regarding district wise PBW infestation.

\begin{tabular}{ccccccc}
\hline & DF & SS & MS & F value & Pr. (>F) & \\
\hline District & 18 & 327.1 & 18.2 & 11.28 & $<2 \mathrm{e}-16$ & $* * *$ \\
Week & 15 & 686.6 & 45.8 & 28.41 & $<2 \mathrm{e}-16$ & $* * *$ \\
Plot & 1 & 439.5 & 439.5 & 272.87 & $<2 \mathrm{e}-16$ & $* * *$ \\
Residuals & 1629 & 2624 & 1.6 & & & \\
\hline
\end{tabular}

*** = highly significant.

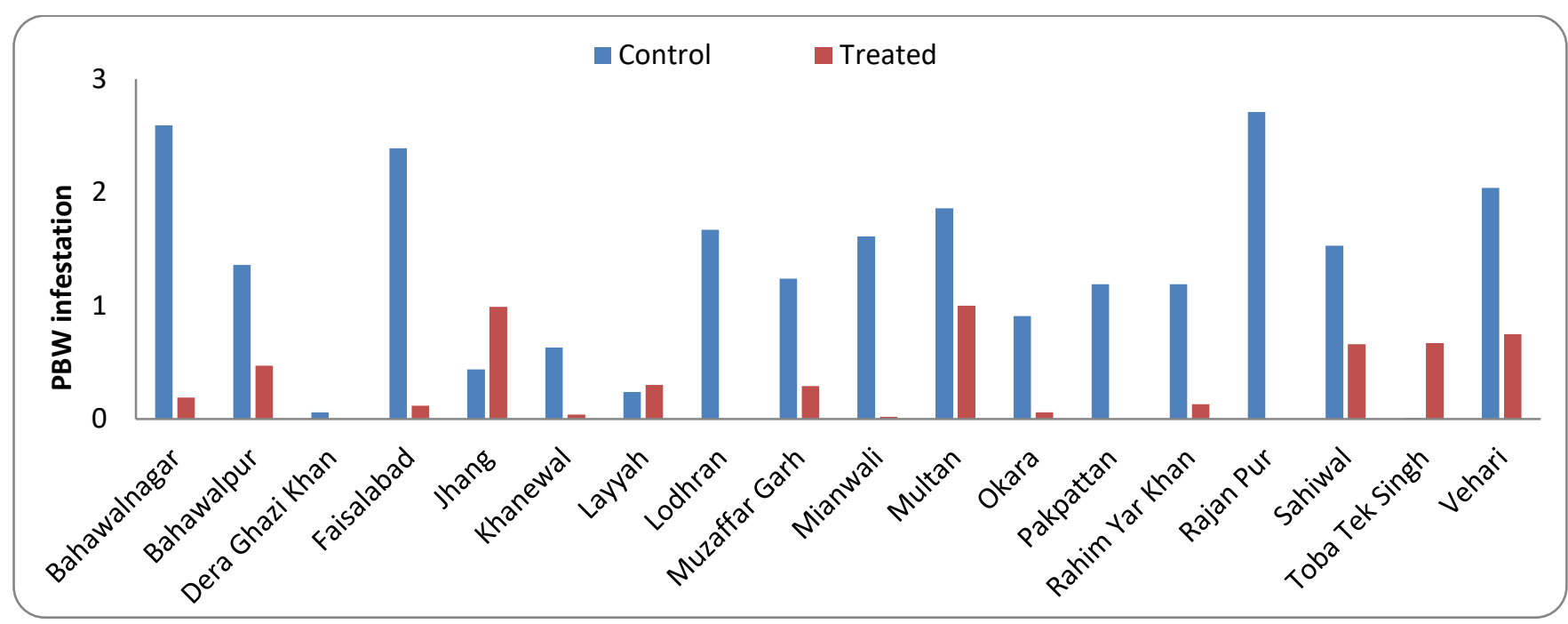

Figure 1. District wise boll infestation by pink bollworm larvae in the major cotton growing districts of Punjab.

Week wise infestation by pink bollworm: The week wise infestation of pink bollworm was found significantly different $(<0.001 \%)$ during the season (Table 1). Figure 2 indicates that the infestation level on the control plots from $1^{\text {st }}$ week of July to $3^{\text {rd }}$ week of August remained in between 0.18 to $0.77 \%$ as compared to treated plots from 0.14 to $0.13 \%$ respectively which gradually increased in control plots from 1.47 to $3.00 \%$ and in treated plots from 0.29 to $0.74 \%$ from $1^{\text {st }}$ week of September to $4^{\text {th }}$ week of October.

Percent infestation in leftover bolls: The ANOVA regarding district wise infestation of pink bollworm of 
the leftover bolls to observe the presence of alive larvae in the leftover bolls is given in Table 2. The maximum occurrence of $9 \%$ was found in control fields of district Sahiwal while the presence of pink bollworm larvae in leftover bolls collected from treated plots was found 1.0\%. In Okara and Pakpattan districts, the presence of pink bollworm in leftover bolls collected from control plots was $5 \%$ and $3.5 \%$ respectively as compared to treated plots which was quite nominal and did not appear in graphical presentation. The presence of larvae in leftover bolls in control plots collected from Mianwali was observed $2.5 \%$ as compared to $0.02 \%$ in the treated plots followed by Rahim Yar Khan as $0.90 \%$ versus $0.25 \%$ in the treated plots (Figure 3 ).

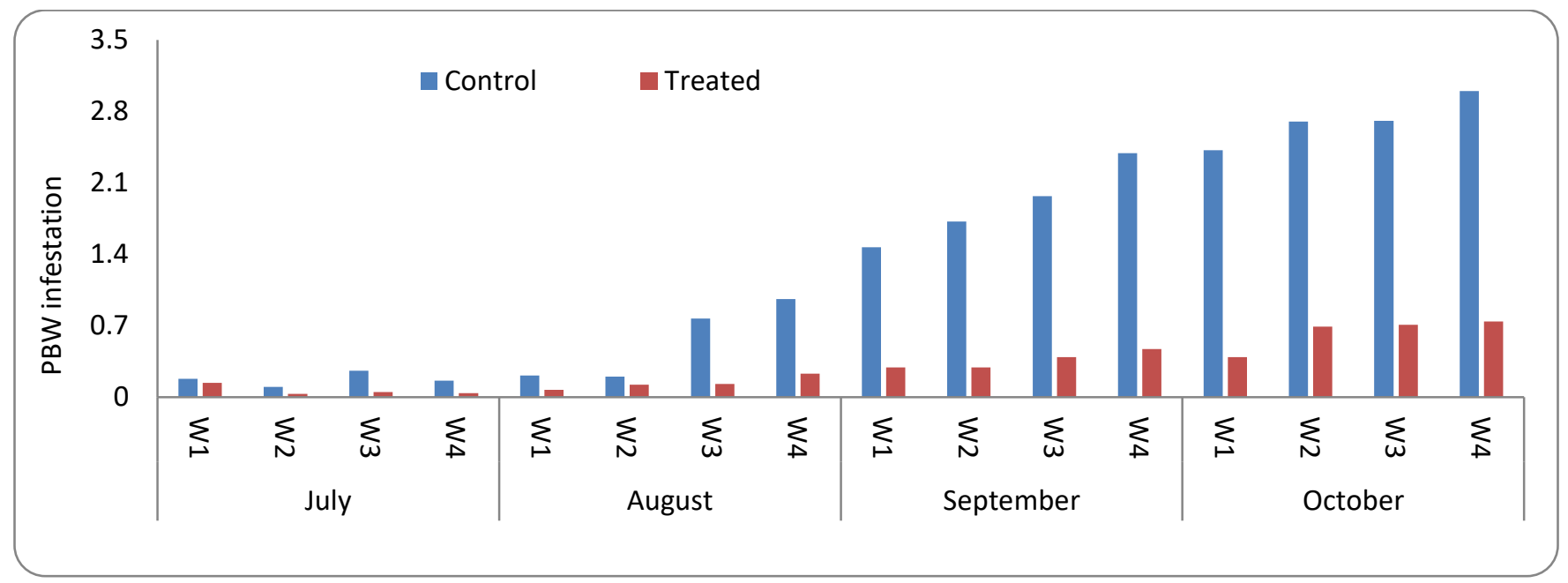

Figure 2. Week wise infestation by pink bollworm larvae during the months of July to October.

Table 2. Analysis of variance regarding district wise PBW infestation of leftover bolls.

\begin{tabular}{lcccccc}
\hline & DF & SS & MS & F value & $\operatorname{Pr}(>\mathrm{F})$ & \\
\hline District & 18 & 97 & 5.389 & 5.577 & $2.23 \mathrm{E}-08$ & $* * *$ \\
Plot & 1 & 19.3 & 19.298 & 19.972 & $2.44 \mathrm{E}-05$ & $* * *$ \\
Residuals & 84 & 81.17 & 0.966 & & & \\
\hline
\end{tabular}

*** = highly significant.

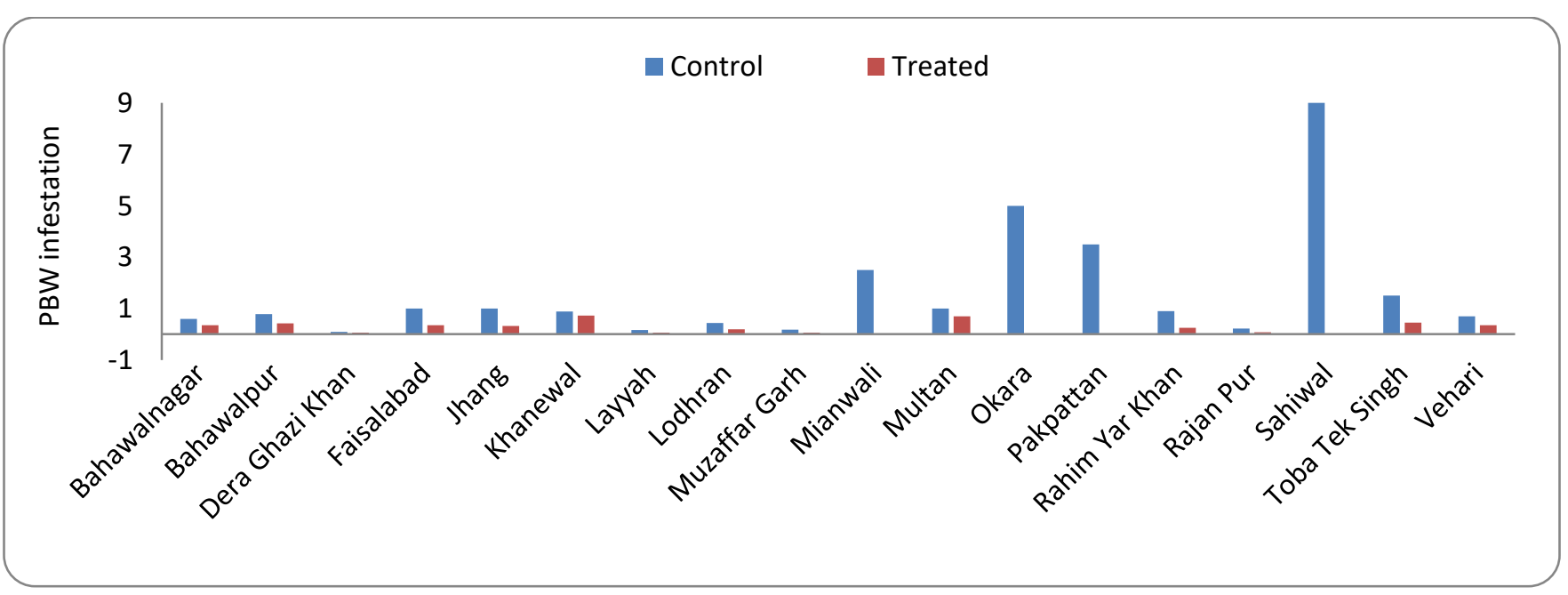

Figure 3. District wise infestation of pink bollworm larvae in the leftover bolls in the major cotton growing districts of Punjab. 
Yield of cotton: The ANOVA regarding cotton yield in the control and treated fields showed highly significant results as shown in Table 3. The data showed that treated plots produced more yield compared with the control fields (Figure 4). Lodhran produced up to 44 maunds per acre yield from treated plots as compared to 28 maunds per acre from control plots followed by Khanewal as 32 maunds per acre from treated plots and 25 maunds from control plots whereas district Muzaffar Garh offered a minimum of 24 maunds from treated plots as compared to 23 maunds per acre from control fields.

\section{DISCUSSION}

The study revealed that overall infestation by pink bollworm in all the control plots was considerably more than that of the treated plots due to installation of $\mathrm{PB}$ ropes for the first time in cotton growing areas of Punjab, Pakistan. The PB rope (male disruption technique) effectively lowered the pink bollworm population in treated fields. Infestation of pink bollworm in fields and in leftover bolls was recorded significantly higher in control plots as compared to treated plots. Our results coincide with the findings of Radhika and Sahadeva (2006) who recorded moth catches in the untreated control plots comparatively higher during the crop season as compared to PB rope treated plots.

Table 3. Analysis of variance regarding district wise cotton yield in treated and control fields.

\begin{tabular}{lcccccc}
\hline & DF & SS & MS & F value & $\operatorname{Pr}(>\mathrm{F})$ & \\
\hline District & 18 & 695.2 & 38.6 & 3.563 & 0.00498 & $* * *$ \\
Plot & 1 & 528 & 528 & 48.71 & $1.62 \mathrm{E}-06$ & $* * *$ \\
Residuals & 18 & 195.1 & 10.8 & & & \\
\hline
\end{tabular}

*** = highly significant.

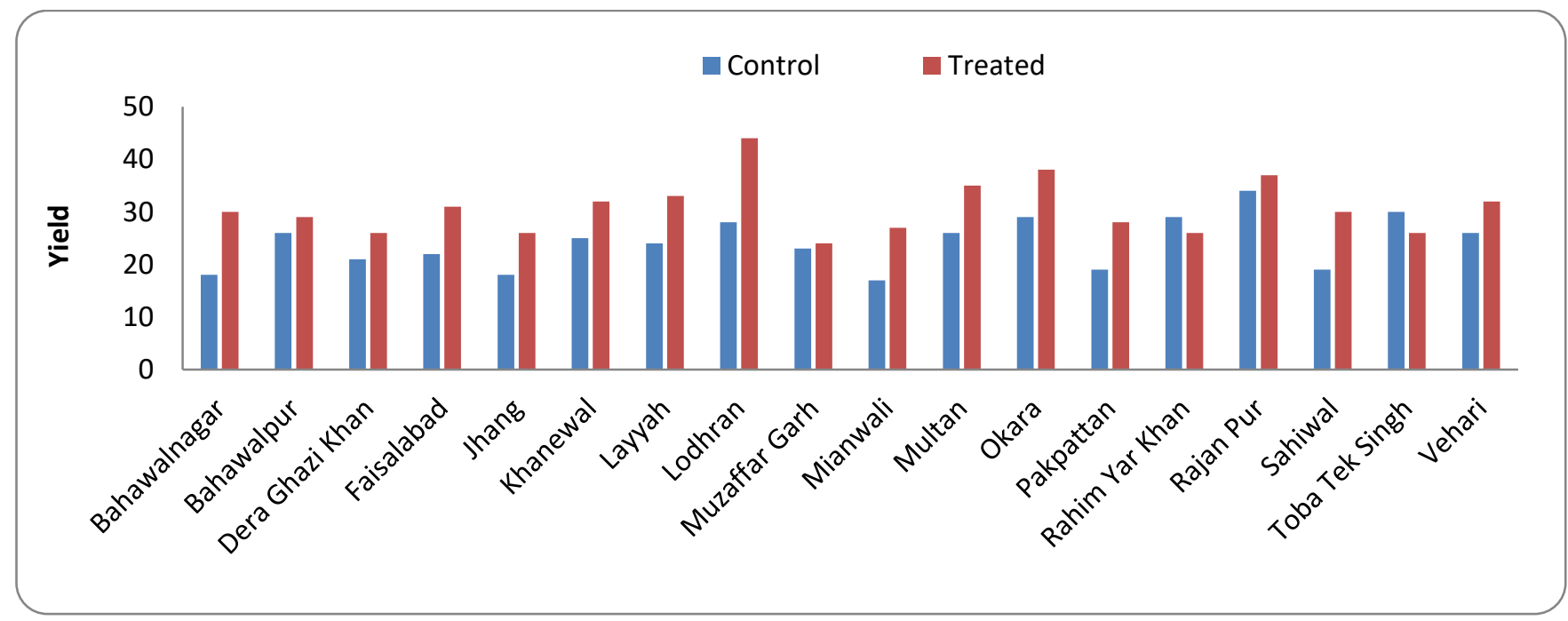

Figure 4. District wise cotton yield in treated and control fields in the major cotton growing districts of Punjab.

The PB rope treated plots were in lowest number of damaged bolls and locules as compared to control plot. Our results are also parallel to the findings of Lykouressisa et al. (2005) who determined the efficacy of mating disruptors by monitoring population of pink bollworm with pheromone baited traps as well as by sampling flowers and bolls to record the damage levels in cotton fields in 1988 and 1999 in central Greece. The treated fields were compared with the control fields in which 2 to 3 insecticides sprays were applied. Sufficient gossyplure for reducing moth catches in traps was present in pheromone dispensers even after 90 days. Our findings are also similar to the study of Lykouressis et al. (2004) who observed the mating disruption effects on population dynamics and percentage of damage caused by pink bollworm. The results revealed that moth catches were highly reduced in the treated fields and mid-season installation of dispensers was successful. They also found that the 5 hectare field was the adequate for the effective implementation of mating 
disruption technique. Damage percentage was significantly less in the treated field as compared to the untreated fields. Farmers' fields in cotton growing areas showed a significant difference in terms of average yield @ 31.57 maunds per acre from the PB rope treated plot as compared to average yield @ 24.10 maunds per acre from the control plot with approximate $31 \%$ increase in yield. The results proved that infestation in leftover bolls from treated plots was found to be $0.306 \%$ while in nontreated plots it was $1.56 \%$ with a difference of $1.259 \%$ (80\% reduction in damage of leftover bolls of treated plots). These results are in accordance with the findings of Patil et al. (2004). Radhika and Sahadeva (2006) also recorded 25.14 maunds per acre in PB rope treated plots as compared to 22.45 maunds per acre in control plots.

\section{CONCLUSION}

It is concluded that installation of $100 \mathrm{~PB}$ rope dispensers per acre reduced the pink bollworm infestation in bolls and leftover bolls to a significant level, having a positive impact on yield. However, the use of mating disruption technique may prove to be very helpful in reducing not only the number of spray applications but also saving the beneficial fauna being environment friendly. It is strongly recommended that mating disruption technique should be adopted throughout cotton growing areas of Punjab, Pakistan for the best management of Pectinophora gossypiella.

Authors' contribution: ZAG, HA, and FA conceived and designed the study; ZAG and HA collected and analyzed the data; ZAG and HA wrote the initial draft; All the authors reviewed, edited and approved the final version of the paper.

Conflict of Interest: The authors declare no conflict of interest.

\section{REFERENCES}

Abro, G.H., Syed, T.S., Tunio, G.M., Khuhro, M.A., 2004. Performance of transgenic BT cotton against insect pest infestation. Biotechnology 3, 75-81.

Agarwal, R.A., Katiyar, K.N., 1979. An estimate of losses of seed kapas and seed due to bollworms on cotton in India. Indian Journal of Entomology 41, 143-148.

Bakhsh, K., Hassan, I., Maqbool, A., 2005. Factors affecting cotton yield: A case study of Sargodha (Pakistan). Journal of Agriculture and Social Sciences 1, 332-334.

Buchelos, C.T., Athanassiou, C.S., Papapostolou, C.T., Georgiou, A., 1999. Correlation between the number of adult male: Pectinophora gossypiella (Saund.) (Lep., Gelechiidae) catches on pheromone traps and the rate of infestation in fruiting bodies of cotton plants by young larvae in three regions of central Greece. Journal of Applied Entomology 123, 433-436.

Byers, J.A., Steven, E.N., 2014. Detection and monitoring of pink bollworm moths and invasive insects using pheromone traps and encounter rate models. Journal of Applied Ecology 51, 1041-1049.

Campion, D.G., Nesbitt, B.R., 1982. Recent advances in the use of pheromones in developing countries with particular reference to mass-trapping for the control of the Egyptian cotton leafworm Spodoptera littoralis and mating disruption for the control of pink bollworm Pectinophora gossypiella. Les Mediateurs Chimiques Agissant sur le Comportement des Insectes., Symposium International, Institut National de la Recherche Agronomique, Paris, pp. 335-342.

Darling, H.S., 1951. Pink bollworm, Platyedra gossypiella (Saund.), as a pest of cotton at Zeidab, northern Sudan. Bulletin of Entomological Research 42, 157-167.

El-Deeb, Y.A., El Hamaky, M.A., Moawad, G.M., 1993. Large scale use of pink bollworm sex pheromone formulations integrated with conventional insecticides for the control of cotton Pests in Egypt. IOBC/WPRS Bulletin 16, 213-219.

Flint, H.M., Merkle, J.R., Yamamoto, A., 1985. Pink bollworm (Lepidoptera: Gelechiidae): field testing a new polyethylene tube dispenser for gossyplure. Journal of Economic Entomology 78, 1431-1436.

Henneberry, T.J., Naranjo, S.E., 1998. Integrated management approaches for pink bollworm in the southwestern United States. Integrated Pest Management Reviews 3, 31-52.

Hummel, H.E., Gaston, L.K., Shorey, H.H., Kaae, R.S., Bryne, J.K., Silverstein, R.M., 1973. Clarification of chemical status of the pink bollworm sex pheromone. Science 181, 873-875.

Hussain R., 2017. Pest Scouting Methods In Cotton Is Crucial To Your Higher Yield. Available at: http://www.agriculture.pk/pest-scoutingmethods-cotton/.

Ingram, W.R., 1994. Pectinophora (Lepidoptera: Gelechiidae). In: Matthews G.A, Tunstall J.P (eds) Insect pests of cotton. University Press, 
Cambridge.

Kannan, M., Uthamasamy, S., Mohan, S., 2004. Impact of insecticides on sucking pests and natural enemy complex of transgenic cotton. Current Science 86, 726-729.

Kehat, M., Anshelevich, L., Gordon, D., Harel, M., Zilberg, L., Dunkelblum, E., 1999. Effect of density of pheromone sources, pheromone dosage and population pressure on mating of pink bollworm, Pectinophora gossypiella (Lepidoptera: Gelechiidae). Bulletin of Entomological Research 89, 339-345.

Lykouressis, D., Perdikis, D., Michalis, C., Fantino, A., 2004. Mating disruption of the pink bollworm Pectinophora gossypiella (Saund.) (Lepidoptera: Gelechiidae) using gossyplure PB-rope dispensers in cotton fields. Journal of Pest Science 77, 205210.

Lykouressisa, D., Perdikisa, D., Samartzisa, D., Fantinoub, A., Toutouzas, S., 2005. Management of the pink bollworm Pectinophora gossypiella(Saunders) (Lepidoptera: Gelechiidae) by mating disruption in cotton fields. Crop Protection 24, 177-183.

Parmar, V.R., Patel, C.C., 2016. Pink Bollworm: a notorious pest of cotton: a review. . AGRES-An International e-Journal 5, 88-97.

Patil, B.V., Bheemanna, M., Hanchinal, S.G., Anandkumar, V., 2004. Management of Cotton Pink bollworm using PB Rope L mating disruptant., Strategies for Sustainable Cotton Production- A Global Vision, University of Agricultural Sciences, Dharwad, Karnataka (India), pp. 172-175.

Radhika, P.I., Sahadeva, R.B., 2006. Management of pink bollworm, Pectinophora gossypiella (Saunders) with PB rope L and IPM approach. Asian Journal of Biological Sciences 2, 68-69.

Staten, R.T., Flint, H.M., Waddle, R.C., Winter, E.Q., Zariti, R.E., Finnell, G.M., Hernandez, M., Yamomoto, A., 1987. Pink bollworm (Lepidoptera: Gelechiidae): large-scale field trials with high rate gossyplure formulation. Journal of Economic Entomology 80, 1267-1271.

Urquijo, C.J.L., Manzano, G.V., 2002. Mating disruption strategies for the control of pink bollworm (Pectinophora gossypiella Saunders) in cotton fields. Boletin de Sanidad Vegetal Plagas 28, 193198. 